\title{
Sensorimotor Perineuritis - An Autoimmune Disease?
}

\author{
Christopher N. Bourque, Brian A. Anderson, \\ C. Martin del Campo, Anders A. F. Sima*
}

ABSTRACT: The literature contains a single description of sensory perineuritis (Asbury et al 1972). These patients demonstrated a painful, distal, sensory neuropathy, and examination of peripheral nerve biopsies revealed focal thickening and inflammatory infiltrates of the perineurium. We report a patient with sensorimotor peripheral nerve dysfunction, accompanied by progressive slowing of nerve conduction velocity. Examination of a sural nerve biopsy demonstrated focal thickening of the perineurium, inflammatory infiltrates, and necrosis of perineurial cells. Immunohistology revealed a patchy precipitation of IgG and IgM on perineurial cells. Ultrastructurally, mononuclear cells were found adjacent to perineurial cells undergoing necrosis. The patient showed gradual improvement partially coinciding with a course of steroid therapy. We suggest that this neuropathy is caused by damage to the perineurial barrier possibly by an immune-mediated destruction of perineurial cells and subsequent compression of the endoneurial content by perineurial scarring.

RÉSUMÉ: La périnévrite sensorielle-motrice: une maladie autoimmunologique? La littérature comprend une seule description de la périnévrite sensoriellemotrice (Asbury et al, 1972). Ces patients ont été mis en évidence une névropathie sensorielle douleureuse distale, et l'examen de biopsies des nerfs périphériques dévoilèrent un épaississement focal et des infiltrations inflammatoires du périnévrium. Nous rapportons un patient atteint d'un dysfonctionnement sensoriel-moteur des nerfs périphériques, accompagné d'un ralentissement progressif en vélocité de conduction des nerfs. Une biopsie du nerf sural montra un épaississement focal du périnévrium, des infiltrations inflammatoires, et la nécrose des cellules périnévriales. L'immuno-histologie révéla un précipitation inégale d'IgG et d'IgM sur des cellules périnévriales. L'examen ultrastructural montra aussi des cellules mononucléaires, trouvées adjacentes aux cellules périnévriales qui dévennaient nécrotiques. Le patient a ressenti une amélioration graduelle, coïncident partiellement avec une course de thérapie à stéroïdes. Nous proposons que cette névropathie est produite par une blessure de la barrière périnévriale vraisemblablement par une destruction des cellules périnévriales par l'entremise d'immunologie et la compression subséquente du contenu endonévriale.

Can. J. Neurol. Sci. 1985; 12:129-133

Specific disorders of the perineurium are rare. In 1972 Asbury and co-workers reported two patients with a chronic, distal, painful, sensory neuropathy related to random perineurial inflammation, scarring, and compression of enclosed endoneurial contents. They named it sensory perineuritis. The condition was unresponsive to steroid therapy. Additional cases have not been reported. We describe a patient who demonstrated both sensory and motor nerve involvement and who showed almost complete remission following, but not necessarily due to, steroid therapy. The pathological observations made by Asbury are amplified, and we postulate a possible immunemediated etiology for this disorder.

\section{CASE Report}

A 52 year old Caucasian male was well until May 1982, when he suffered a myocardial infarction. After two weeks of uncomplicated recovery, he developed shoulder paresthesiae which progressed over several weeks to involve his arms and hands. A few weeks later, he noted numbness of his shins, with needle-like pain radiating up both legs and burning discomfort over the soles of his feet, accentuated by pressure. By mid-August he complained of aching pain in his shoulders, arms, and hands. In early September he noted progressive weakness in all limbs. His medications included a triamterene-hydrochlorothiazide combination, a hydrochlorothiazide-reserpine combination, and timolol maleate. Until his infarct, he drank approximately 13 ounces of hard liquor per week.

He was first examined four months after the symptoms began. Cranial nerves were normal. He had diffuse muscle wasting, especially of shoulder girdles and calves, and generalized weakness. Fasciculations were not seen. Tendon reflexes were diminished at the knees and absent at the ankles. He had severe distal hyperesthesia and walked with considerable pain. There was impairment of pinprick and light touch in a stocking-glove distribution and loss of vibration and position sense in the toes.

From the Department of Medicine, Section of Neurology, St.Boniface General Hospital and the Department of Pathology*. Section of Neuropathology, Health Sciences Centre. Winnipeg.

Received June 14, 1984. Accepted in revised form March 6, 1985.

Reprint Requests to: Dr. Brian A. Anderson, Section of Neurology, St.Boniface General Hospital, 409 Tache Avenue, Winnipeg, Manitoba, Canada R2H 2A6. 
Laboratory investigation revealed a mean red cell corpuscular volume of 101.3 Fl. $(\mathrm{N}=80-90 \mathrm{Fl}$.), with normal hemoglobin, vitamin $\mathrm{B} 12$, and folate levels. The following investigations were normal; fasting blood glucose, sedimentation rate, serum protein electrophoresis, serum thyroxine, rapid plasma reagent test for syphilis, 24-hour urine collection for uroporphyrins and corproporphyrins, and serum, urine, and hair and nail clippings for arsenic and lead levels. Cerebrospinal fluid examination showed two lymphocytes $/ \mathrm{mm}^{3}\left(\mathrm{~N} \leqslant 5 / \mathrm{mm}^{3}\right)$, protein 0.6 $\mathrm{g} / \mathrm{L}(\mathrm{N} \leqslant 0.40 \mathrm{gm} / \mathrm{L})$ and normal glucose. Biopsies of the gastrocnemius muscle and the sural nerve were performed.

Serial electromyographic and nerve conduction studies showed progressive impairment of motor nerve conduction velocities with prolonged distal latencies, and marked delay over pressure points (Table 1). Sensory nerve conduction times were unrecordable. Electromyographic examinations showed fibrillations and positive sharp waves in upper and lower extremity musculature, consistent with denervation.

In October 1982, prednisone $80 \mathrm{mg}$. daily was begun and then tapered over four weeks to $20 \mathrm{mg}$. every other day. He continued to deteriorate with complete loss of sweating over the palms and feet. After four weeks of prednisone, he noted some improvement in pain and gait. By late November 1982, he was free of pain, showed increased strength, and experienced return of sweating and sensation in his feet. In January 1983 his medication was discontinued. He showed further improvement and returned to work full time by May 1983. The electromyographic and nerve conduction studies showed some reinnervation and improved conduction velocities (Table 1). By July 1983, approximately 14 months after the onset of his symptoms, he complained only of mild burning paresthesiae of his feet after prolonged walking, and mild generalized weakness. Neurological examination was normal except for diminished tendon reflexes at the knees and ankles.

\section{PATHOLOGICAL Findings:}

\section{Methods}

One portion of the gastrocnemius muscle biopsy was formalinfixed and paraffin-embedded. Another portion was frozen for histochemical examination. The sural nerve was formalin-fixed and paraffin-embedded. Sections were stained with hemotoxylineosin, luxol-fast-blue, Bodian silver stain, and peroxidaseantiperoxidase diluted in tris buffer for $\mathrm{IgG}$ (dilution $1 / 200$ ), IgM (1/100), C3 (1/100), and albumin (1/100). Control stains were prepared using normal rabbit serum. Tissue for electron microscopy was fixed in $2.5 \%$ glutaraldehyde in cacodylate buffer ( $\mathrm{pH} 7.15$ ), post-fixed in $1 \%$ osmic acid in cacodylate buffer, dehydrated in alcohol, and embedded in epoxy resin. Ultrathin sections were stained with lead citrate and uranyl acetate. Morphometric analysis of the nerve included myelinated fiber size spectrum, mean fiber size, fiber density, and fiber occupancy. An age- and sex matched control nerve for morphometry was obtained at autopsy from a patient with no known neurologic disease.

\section{Light Microscopic Findings}

Light microscopic examination of hemotoxylin-eosin stained sections of the gastrocnemius muscle showed no changes suggestive of denervation or an inflammatory process involving muscle, connective tissue, or blood vessels. Histochemical examination was unremarkable. The most striking light microscopic changes of the sural nerve were marked, focal thickening of the perineurium (Figure 1). Its layers were spread apart with intervening deposition of collagen, amorphous material, and inflammatory infiltrates, consisting of histiocytes and lymphocytes

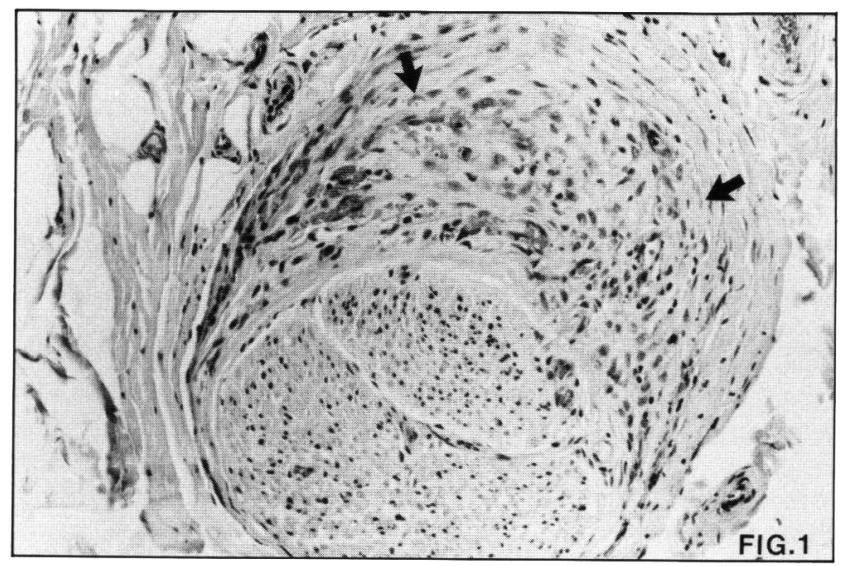

Figure I - Focal perineurial thickening (arrows) in a fascicle of sural nerve. Epineurium and endoneurium are not involved. $H \& E, X 100$.

TABLE 1: Nerve conduction velocities over a period of 20 months after onset of symptoms.

\begin{tabular}{|c|c|c|c|c|c|c|c|}
\hline & \multirow{2}{*}{ Normals } & \multicolumn{2}{|c|}{1982} & \multicolumn{3}{|c|}{1983} & \multirow{2}{*}{$\begin{array}{l}1984 \\
26 / 1\end{array}$} \\
\hline & & $22 / 9$ & $1 / 12$ & $12 / 1$ & $14 / 2$ & $3 / 5$ & \\
\hline \multicolumn{8}{|l|}{ Lt. Median } \\
\hline M.C.V. & $52-72$ & 52.2 & 41.8 & 30.1 & 32.6 & 35 & 46.9 \\
\hline D.L. & $2.6-4.0$ & 7.5 & 14.8 & 18.2 & 15.8 & 9.0 & 5.4 \\
\hline M.A.P. & $7-17$ & 4 & 2 & 1.5 & 2.0 & 4 & 3 \\
\hline \multicolumn{8}{|l|}{ Lt. Peroneal } \\
\hline M.C.V. & $43-57$ & $* *$ & $* *$ & 18.9 & 17.6 & $*$ & 44.4 \\
\hline D.L. & $3.4-5.0$ & $* *$ & $* *$ & 18.3 & 16.1 & 10.5 & 5.6 \\
\hline M.A.P. & $6-12$ & $* *$ & $* *$ & 0.2 & 0.1 & 0.6 & 1 \\
\hline
\end{tabular}

M.C.V. - Motor Conduction Velocity $(\mathrm{M} / \mathrm{sec})$,

D.L. - Distal Latency (msec).

M.A.P. - Amplitude of Muscle Action Potential $(\mathrm{mV})$.

* $\quad$ Not recorded.

** $\quad$ No response obtained from recordings in extensor digitorum brevis. 
(Figure 2). Immunoperoxidase stains revealed areas of focal positivity for $\operatorname{IgG}$ and $\operatorname{IgM}$ within the perineurium (Figure 3 ). No deposits of IgA, C3, or albumin were demonstrated. Control stains using rabbit serum showed no deposition. Occasional arterioles were surrounded by a mononuclear cell infiltrate, but no vessel wall infiltration was seen.

The endoneurial content showed axonal atrophy with redundant and wrinkled myelin sheaths which at times showed splitting and degeneration. The occasional onion-bulb formation around myelinated fibers was demonstrated. No inflammatory cells were seen within the endoneurium.

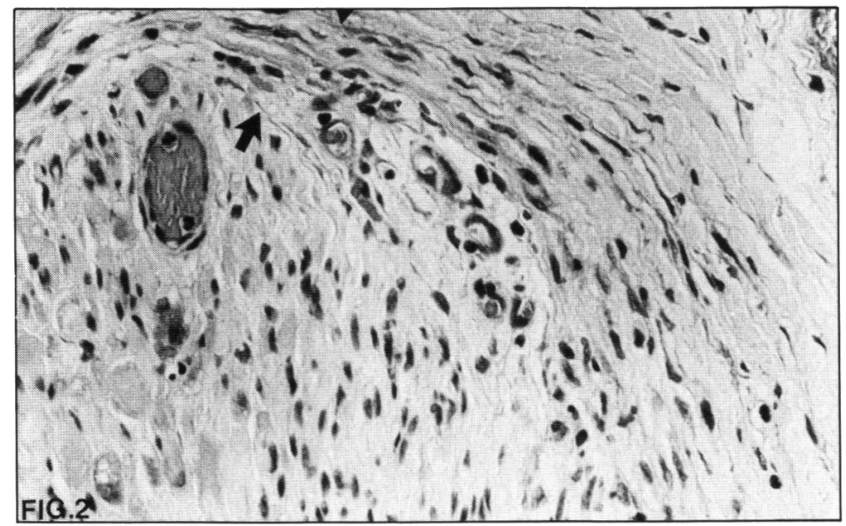

Figure 2 - Perineurial laminae (arrowheads) are spread apart. Mononuclear cells, fibroblasts and amorphous material intervene. $H \& E X 400$.

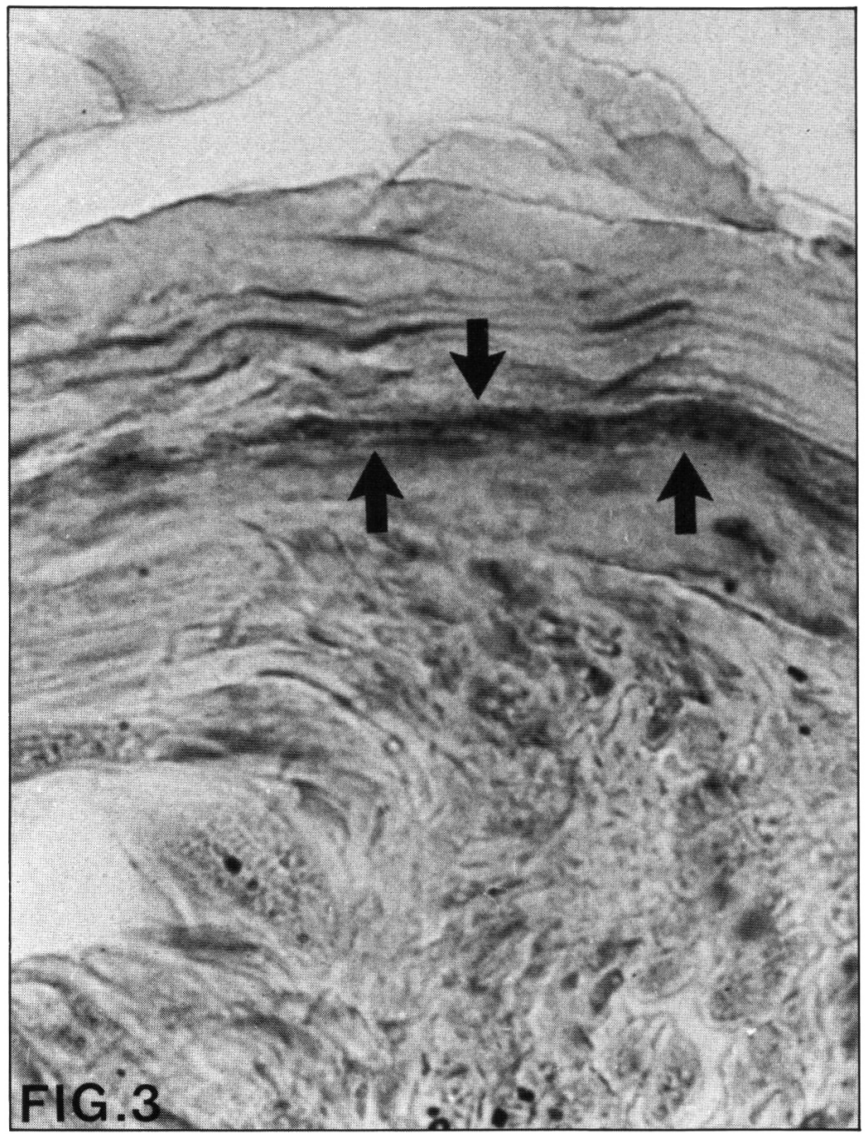

Figure 3 - Focal deposit of $\lg G$ within the perineurium (arrows). Immunoperoxidase, $X 400$.

\section{Ultrastructural Findings}

Electron microscopic examination showed necrotic perineurial cells, breaching of the perineurial laminae, and separation of the laminae by increased numbers of collagen fibers (Figure 4). The laminae were covered by thickened basement membranes. Attached to the basement membranes there were irregular accumulations of a moderately electron-dense filamentous material (Figure 5). Perineurial vessels were surrounded by lymphocytes and clusters of histiocytes. The latter cells retained their individual plasma membranes, but their configuration was

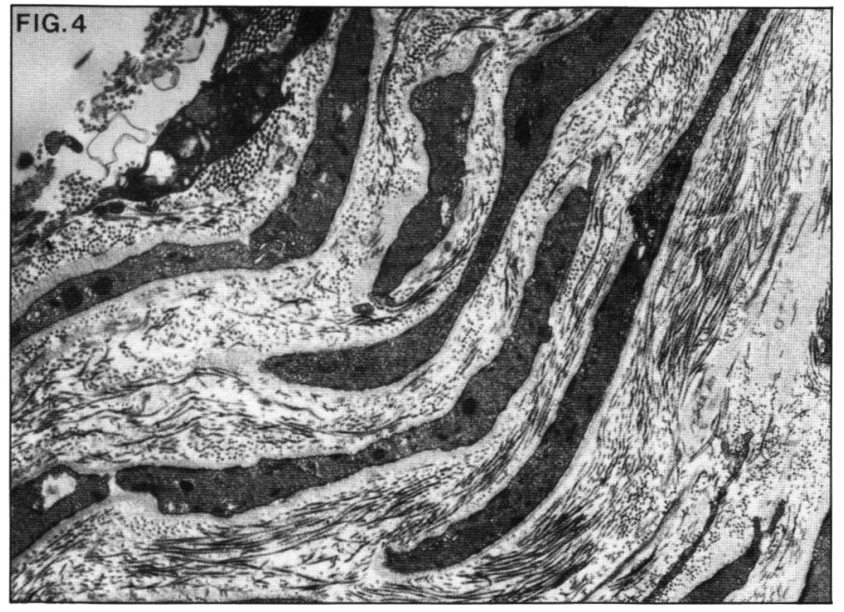

Figure 4 - Perineurium showing breaches in the perineurial laminae and increased collagen deposition XI0.350.

suggestive of giant cell formation. Lymphocytes were often seen in close juxtaposition to perineurial cells undergoing necrosis (Figure 6).

The myelinated fiber population was decreased. Preserved myelinated fibers commonly showed atrophic axons surrounded by wrinkled myelin sheaths. Honey-combed profiles were occasionally demonstrated. Other axons showed acute axonal degeneration. Unmyelinated fibers often showed a one-to-one Schwann cell: axon relationship and Schwann cell banding. Onion-bulb formations by slender axon-containing Schwann cell processes around myelinated fibers were commonly seen. Endoneurial vessels were unremarkable, with endothelial cells maintaining intact tight junctions. The endoneurial space showed excessive collagen deposition but did not contain any inflammatory cells.

\section{Morphometric Findings}

Size frequency distribution of the myelinated fiber population showed a normal bimodal fiber size distribution. However, the mean myelinated fiber size measured $39 \mu \mathrm{m}^{2}$ as compared to $49 \mu \mathrm{m}^{2}$ in the age-matched control nerve. Myelinated fiber density was calculated to 6,539 myelinated fibers $/ \mathrm{mm}^{2}$, similar to that of the control nerve, which contained 6,996 myelinated fibers $/ \mathrm{mm}^{2}$. On the other hand, myelinated fiber occupancy of the endoneurial space was reduced to $25.5 \%$, the normal being $34.0 \%$.

\section{Discussion}

The clinical course of our patient differed from Asbury's patients. Our patient demonstrated prominent motor involvement and symptoms evolved over months, whereas symptoms in Asbury's patients evolved over three years or more. After the 


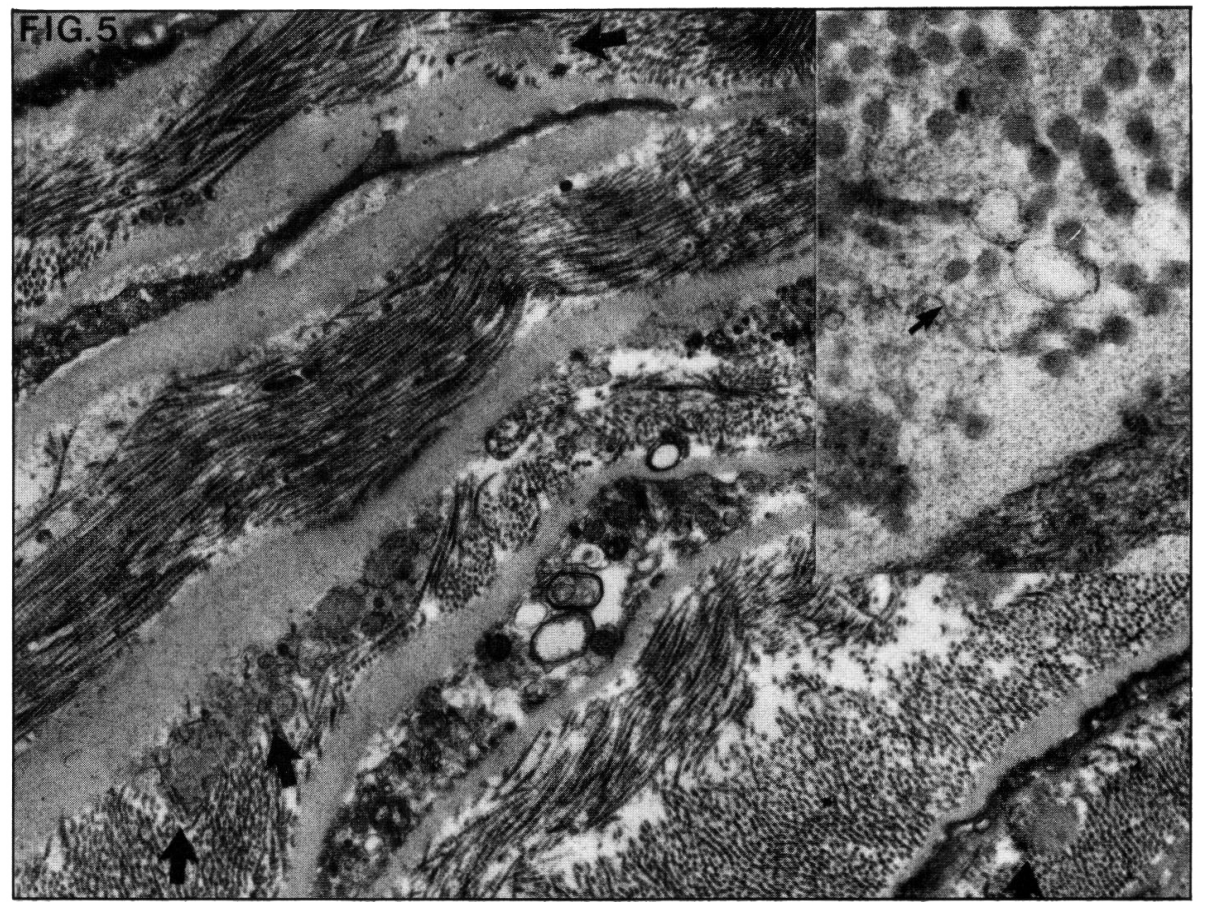

Figure 5-Perineurial cells are surrounded by markedly thickened basement membranes on which there is precipitation of a moderately electron-densefilamentous material (arrows). Also note perineurial cell undergoing necrosis (centre). X10,350. Inset shows higher magnification of filamentous material (thin arrow) deposited on basement membrane $X 85,800$.

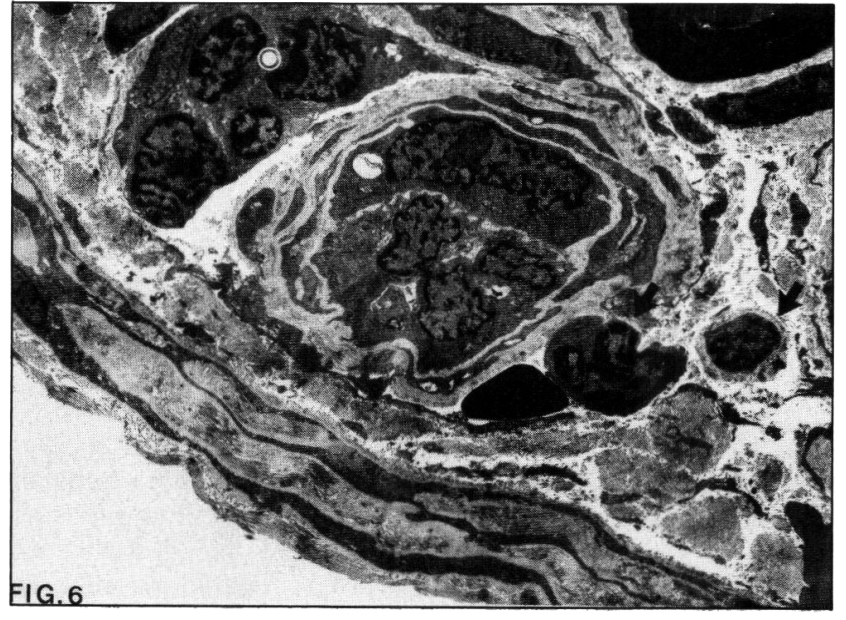

Figure $6-$ Perineurial vessel showing swollen endothelial cells surrounded by a cluster of histiocytes (white dot). Note lymphocytes in close apposition to perineurial cells undergoing necrosis (arrows). X4,370.

initiation of steroid therapy, our patient showed further deterioration over several weeks and then began to improve. This improvement continued after steroids were discontinued. Thus, we cannot conclude that steroid therapy was beneficial. Asbury's patients showed no response to steroid therapy, but they received treatment at a more chronic stage of the disease. The pathological findings were similar, with focal perineurial involvement characterized by disruption of perineurial lamellae, and the presence of an inflammatory infiltrate, consisting of lymphocytes and histiocytes.

One can only speculate as to the pathogenesis of the selective perineurial involvement. An autoimmune phenomenon directed at an antigen in the perineurium seems possible. Such a mechanism is supported in our patient by the deposition of IgM and IgG perineurial cells undergoing necrosis. Thus, destruction of the perineurial cells may follow a type II antibody-dependent cytotoxic hypersensitivity reaction. The selective deposition of $\mathrm{IgG}$ and $\mathrm{IgM}$ in the perineurium, in the absence of $\operatorname{IgA}, \mathrm{C} 3$, and albumin, argues against a nonspecific deposition of immunoglobulin resulting from a breakdown of the perineurial diffusion barrier. The report by Konishi et al detailing a patient with cryoglobulinemia and perineuritis also raises the possibility of an immunemediated mechanism. ${ }^{2}$

Asbury et al suggested that the degenerative changes of nerve fibers were related to compression by a scarred, thickened, perineurial sheath. 'Alternatively such changes may be initiated in the acute stage by an altered integrity of the perineurial sheath which is regarded as a metabolically active, selective diffusion barrier, intimately concerned with the homeostasis of the endoneurial milieu. ${ }^{3}$ Experimental models in which the perineurium has been stripped or disrupted, have yielded conflicting results regarding the preservation of endoneurial contents. ${ }^{46}$. Nesbitt and Acland demonstrated intact endoneurial contents following careful microsurgical removal of short segments of the perineurium ${ }^{6}$. It is not clear, however, what the effect of a more extensive perineurial damage might have. It is conceivable that the widespread disruption of the perineurial sheath may, in addition, reduce the tensile strength of the nerve leading to mechanical injury in the endoneurium? ${ }^{7}$. In longstanding cases as described by Asbury and co-workers, perineurial fibrosis is likely to further compromise the already adversely affected endoneurial content.

\section{ACKNOWLEDGEMENT}

We wish to thank Dr. R. T. Ross for his constructive criticisms and Mrs. Gail Landry for secretarial assistance.

\section{REFERENCES}

1. Asbury AK, Picard EH, Baringer JR. Sensory perineuritis Arch Neurol 1982; 16: 302-312

2. Konishi T, Saida K, Ohnishi A, et al. Perineuritis in monoeuritis multiplex with cyroglobulinemia. Muscle Nerve 1982; 5: 173-177 
3. Thomas PK, Olsson Y. Microscopic anatomy and function of the connective tissue components of peripheral nerve. In: Dyck PJ, Thomas PK, and Lambert EH, eds. Peripheral neuropathy. Philadelphia: WB Saunders Co, 1975: 168-189

4. Spencer PS, Weinberg HJ, Raine CS, et al. The Perineurial window - A new model of focal demyelination and remyelination. Brain Res 1975; 96: 323-329
5. Pencek TL, SchaufCL, Low PA, et al. Disruption of the perineurium in amphibian peripheral nerve: morphology and physiology. Neurology 1980; 30: 593-399

6. Nesbitt JA, Ackland RD. Histopathological changes following removal of the perineurium. J Neurosurg 1980; 53: 233-238

7. Sunderland S. Nerves and Nerve Injuries. Second edition Edinburgh, London, and New York: Churchill Livingstone, 1978: 64-65 